\title{
Eastward propagation of a plasma convection enhancement following a southward turning of the interplanetary magnetic field
}

Article

Published Version

Lockwood, M., van Eyken, A. P., Bromage, B. J. I., Willis, D. M. and Cowley, S. W. H. (1986) Eastward propagation of a plasma convection enhancement following a southward turning of the interplanetary magnetic field. Geophysical Research Letters, 13 (1). pp. 72-75. ISSN 0094-8276 doi: https://doi.org/10.1029/GL013i001p00072 Available at https://centaur.reading.ac.uk/38912/

It is advisable to refer to the publisher's version if you intend to cite from the work. See Guidance on citing.

Published version at: http://dx.doi.org/10.1029/GL013i001p00072

To link to this article DOI: http://dx.doi.org/10.1029/GL013i001p00072

Publisher: American Geophysical Union

All outputs in CentAUR are protected by Intellectual Property Rights law, including copyright law. Copyright and IPR is retained by the creators or other copyright holders. Terms and conditions for use of this material are defined in the End User Agreement. 


\section{www.reading.ac.uk/centaur}

\section{CentAUR}

Central Archive at the University of Reading

Reading's research outputs online 


\section{EASTWARD PROPAGATION OF A PLASMA CONVECTION ENHANCEMENT FOLLOWING A SOUTHWARD TURNING OF THE INTERPLANETARY MAGNETIC FIELD}

M. Lockwood, A.P. van Eyken, B.J.I. Bromage, D.M. Willis

Rutherford Appleton Laboratory, U.R. and S.W.H. Cowley

Blackett Laboratory, Imperial College, London, U.K.

Abstract. On October 27th 1984, high-latitude ionospheric convection was observed by the European incoherent scatter (EISCAT) radar. For a nine-hour period, simultaneous observations of the interplanetary magnetic field (IMF) were obtained sunward of the Earth's bow shock. During this period, the IMF abruptly turned southward, having previously been predominantly northward for approximately three hours, and a strong enhancement in convection was observed $11 \pm 1$ minutes later. Using the very high time resolution of the EISCAT data, it is shown that the convection enhancement propagated eastward, around the afiernoon magnetic local time sector, at a speed of the order of $1 \mathrm{kms}^{-1}$. These results are interpreted in terms of the effects of an onset of steady IMF-geomagnetic field merging and are the first to show how a new pattern of enhanced convection is established in the high latitude ionosphere.

\section{Introduction}

Many studies have investigated the patterns of high-latitude F-region convection and E-region currents under a variety of orientations of the interplanetary magnetic field (IMF) (eg. Heelis and Reiff,1985; Friis-Christensen et al.,1985). For a northward IMF, the flows are generally much slower and are confined to higher latitudes than when the IMF is southward. In some of these studies the history of the IMF was not considered, and in most of the others the convection patterns were studied for periods when the IMF orientation had been stable over extended periods of up to several hours prior to the convection observations. Nishida (1968) noted that the DP 2 current system was enhanced at high latitudes $7 \pm 1$ minutes after a southward turning of the IMF impinged upon the Earth's bow shock. McPherron and Manka (1985) and Clauer and Kamide (1985) have recently reported similar delays. Enhancements in convection speeds in response to IMF changes have been observed using the Sondrestromfjord incoherent scatter radar with a time resolution of about $25 \mathrm{~min}$. (Clauer et al.,1984).

EISCAT observations of 2.5 -minute resolution allow the lag between the IMF change and the response of F-region convection to be quantified for the first time. Rishbeth at al. (1985) observed a delay which was roughly twice the time expected for the IMF effect to reach the ionosphere. In this letter the same EISCAT data are analysed at even higher time resolution

Copyright 1986 by the American Geophysical Union

Paper number $5 \mathrm{~L} 6743$

$0094-8276 / 86 / 0051-6743 \$ 03.00$ (post-integration periods of 30 seconds). It is shown that the additional delay is consistent with the initial expansion of a new enhanced convection pattern.

\section{Observations}

The U.K. Special Programme "POLA" uses the EISCAT radar to study high-latitude plasma convection in the F-region of the ionosphere at invariant latitudes between about $71^{\circ}$ and $75^{\circ}$. The experiment uses a monostatic beam-swinging technique, signals being transmitted and received at Troms $\varnothing$ along two azimuths $24^{\circ}$ apart (see figure 1). The line-of-sight velocity component, $v_{T}$, is measured in each beam direction with resolution in invariant latitude of about $0.5^{\circ}$. Data for the third range gate are presented here; other gates give similar results but have lower signal-noise ratios. The azimuths were chosen such that, for the same range, the two scattering volumes are centred at the same invariant latitude (van Eyken et al.,1984). Gate 3 is at an invariant latitude of $72.0^{\circ}$ and the spatial separation of the scattering volumes for the two azimuths, $\Delta x$, is $281 \mathrm{~km}$. Observations are made in a 5 -minute cycle: eight 15-second pre-integrated data dumps are recorded for azimuth 1 ; these are followed by thirty seconds during which the Troms $\varnothing$ antenna is in motion and a further eight 15 -second data dumps for azimuth 2 ; the cycle ends with a second 30-second period during which the antenna returns to azimuth 1 . In van Eyken et al. (1984) and Rishbeth et al. (1985) line-of-sight components were combined to derive velocity vectors with 2.5-minute resolution. In this letter only the directly-measured line-of-sight velocity components and the ion temperatures are studied, but at higher (30-second) time resolution.

For a nine-hour period on October 27th, 1984, simultaneous observations of the IMF were obtained from the UK satellite (UKS) of the Active Magnetospheric Particle Tracer Explorer (AMPTE) mission. At 1107UT the IMF abruptly turned southward, having been predominantly northward for the previous three hours. At this time, the UKS was near $18 R_{E}$, upstream of the Earth's bow shock, and the EISCAT scattering volumes were at an MLT of about $1400 \mathrm{hrs}$. Subsequent correlation analys is has shown that the strong increase in westward convection (see figure 1 of Rishbeth et al,1985) occurred $11 \pm 1$ minutes after the southward turning. The initial onset of high convection velocities caused a sharp rise, and subsequent decay, in ion temperatures due to the enhanced ion-neutral frictional heating. The velocity vectors observed before and after the enhancement are drawn from different convection patterns; the data set appears to show 


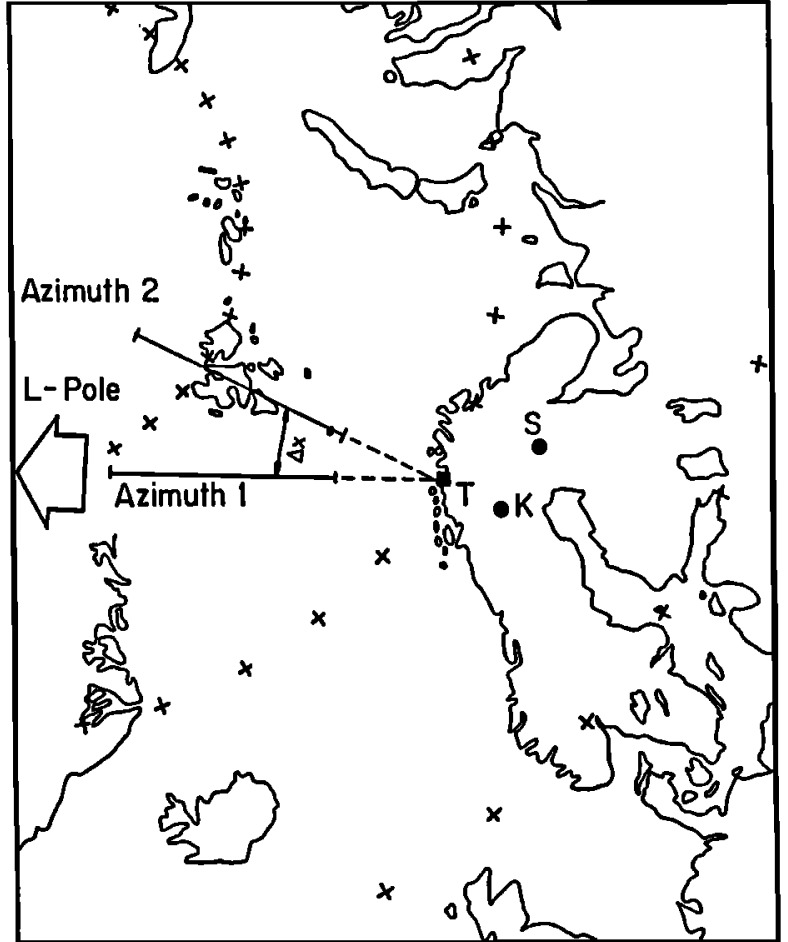

Fig. 1. Map of the EISCAT radar showing the two beam directions employed in the U.K. Special Programme POLA.

the replacement of the low-speed pattern for northward IMF by a southward-IMF pattern.

\section{Results}

Figure 2 shows the ion temperatures, $T_{1}$, and line-of-sight velocities, $v_{T}$, observed in gate 3 for each of the two azimuths shown in figure 1 , for 30 -second post-integration periods. The southward turning of the IMF at 1107UT is marked ST. The change in $v_{T}$ following the IMF turning is seen for azimuth 1 slightly before it is seen for azimuth 2 , i.e. the effect appears to be propagating eastward. To quantify this visual impression, a cross-correlation analys is was carried out for the line-of-sight velocities observed in the two beam directions. This analysis was repeated for the ion temperatures.

The results are given in figure 3 which shows the correlation coefficients, $r$, for $(a), T_{1}$ and (b), $v_{T}$, and the respective $|z / \sigma|$ values, where $z$ is the Fisher-z variable and $\sigma$ is the variance. The significance levels ascribed to the $r$ values, from these $|z / \sigma|$, are overestimates as they assume normal distributions of samples and do not account for the persistence in the $T_{1}$ and $v_{T}$ time series. Values are given as a function of lag $\Delta t$, introduced between the two time series for the two azimuths; the convention adopted for the sense of $\Delta t$ is such that for positive $\Delta t$ the observations for azimuth 2 are lagged: azimuth 1 data for 1115-1139 UT are always used (as marked in figure 2) and are correlated with azimuth 2 data for $(1115+\Delta t)-(1139+\Delta t)$ UT. It can be seen that, for positive $\Delta t$, no correlation coefficients greater than 0.6 are obtained and none are significant at more than the nominal $99 \%$ level. However for negative $\Delta t$, peak correlation coefficients greater than 0.95 are obtained for both $v_{T}$ and $T$ at nominal significance levels greater than the $99.99 \%$ level. This effect was revealed by all gates having sufficient signalnoise ratio to allow 30 -second analys is of the signal spectrum.

Fits were made to the $r-\Delta t$ curves shown in figure 3 , weighted according to the number of samples used to obtain each value of $r$. From these fits, the lags of the peak correlation, $\Delta t_{p}$, were found to be $1.8 \pm 0.2$ minutes and 3.1 \pm 0.2 minutes for the $T_{i}$ and $v_{T}$ enhancements respectively, giving mean eastward velocities, $\Delta x / \Delta t_{p}$, of $2.6 \pm 0.3 \mathrm{kms}^{-1}$ and $1.5 \pm 0.1 \mathrm{kms}^{-1}$. Similar correlation analyses between data from different range gates, for each of the two azimuths, give delay estimates, $\Delta t_{p}$ which correspond to only a smell southward component perpendicular to the L-shell. Hence the changes in $v_{T}$ and $T_{1}$ are propagated slightly south of eastward around the afternoon sector. In the following section these results are interpreted in terms of the expansion of the new enhanced convection pattern.

\section{Discussion}

After three hours of northward IMF, the pattern of convective flows in the polar ionosphere is known to be weak and contracted. Some open flux would still exist, mapping through the distant tail to the IMF. If a southward turning of the IMF then impinges on the magnetopause, dayside field line merging would cause flux tubes sunward of the old polar cap to

October 27, 1984

Gate 3

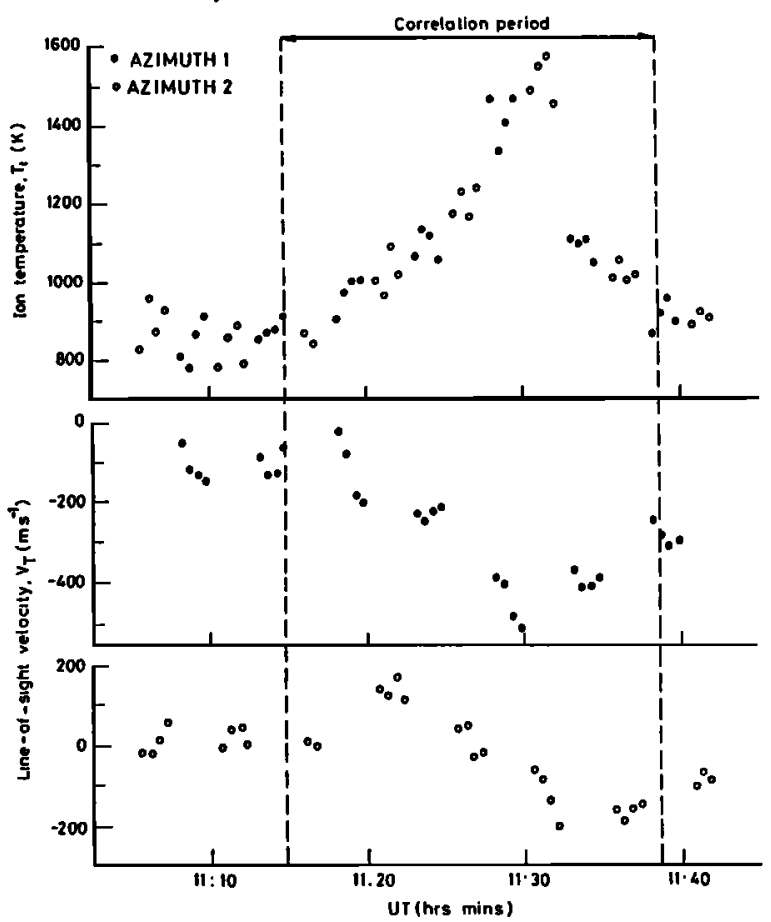

Fig. 2. Ion temperatures, $T_{i}$, and line-of-sight velocities, $v_{T}$, observed for the two POLA azimuths in gate 3 (height $=277 \mathrm{~km}$, invariant latitude $=72.0^{\circ}$ ). The southward turning of the IMF was observed by the AMPTE UKS at 11:07UT. 


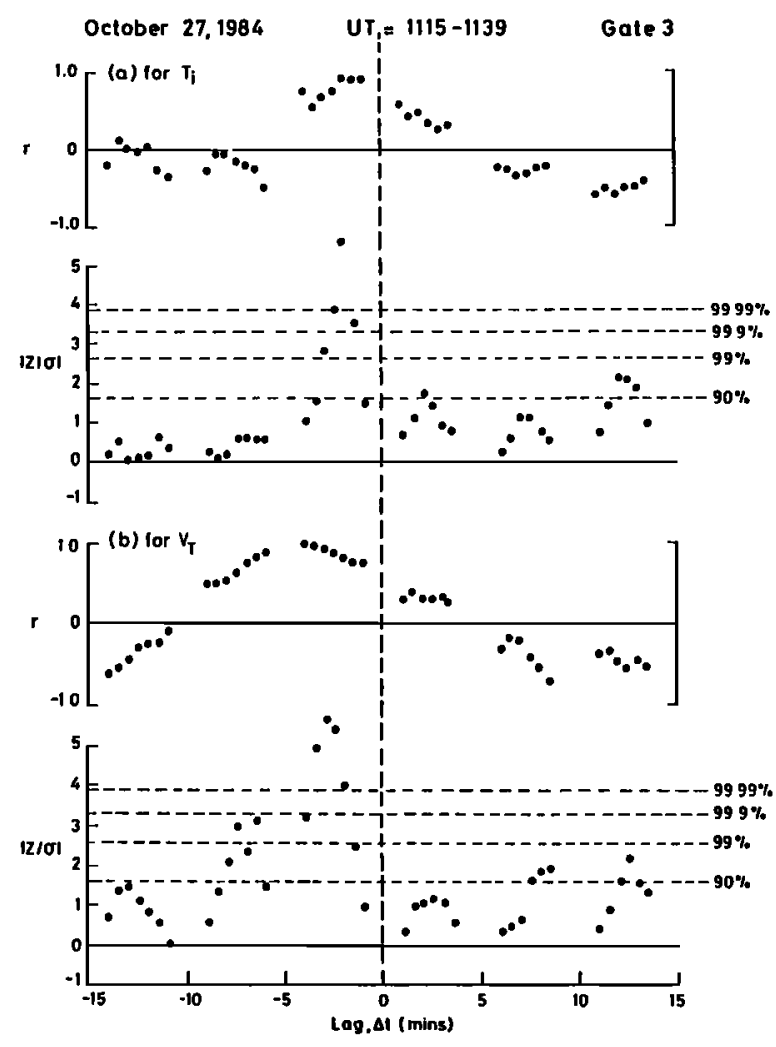

Fig. 3. Correlation coefficients, $r$, between the two azimuths as a function of lag, $\Delta t$, for (a), $T_{1}$ and $(b), v_{T}$. For positive $\Delta t$, the time series for azimuth 2 has been lagged. Also shown are the values of $|z / \sigma|$ (see text).

become open. As additional flux is connected to the IMF, the region of newly-opened field lines expands rapidly outward from a small initial area. Within this region field tension produces anti-solar flow and, as ionospheric flow is incompressible, this generates a new twin-vortex flow pattern, of the kind illustrated in figure 4a; this must also grow rapidly. The flow pattern would be established by the region of newly opened flux via Alfvén waves which propagate perpendicular to the geomagnetic field lines at a speed very much greater than the expansion speed of the open flux boundary. In this way, a new polar cap and a new twin-celled convection pattern might be established following a southward turning of the IMF.

In this section we shall discuss how the EISCAT data presented in the previous section are consistent with these concepts and with the motion of the equipotential contours over the field of view as the new convection pattern expands.

Consider a constant potential difference $D$, applied across a small region of the magnetopause at $t$ ime $t=0$ by the onset of steady IMF geomagnetic field merging. In this letter it is assumed that the the region of the ionosphere where flux is opened to the IMF is elliptical, of semi-axes $a$ and $a \times c$ at time $t$ (see figure 4a). Siscoe and Huang (1985) have performed calculations for the inflation of a circular cap $(c=1)$, however for $t$ near zero an elliptical form may be more general. The total flux connected to the IMF at the time $t$ is given by :

$$
\text { B } \pi c a^{2}=\phi t
$$

where $B_{i}$ is the geomagnetic flux density at ionospheric altitudes. This equation assumes that $t$ is sufficiently small that no open flux is lost from the region by reconnection in the geomagnetic tail. Phenomena associated with enhanced tail reconnection are not observed until about 25-40 minutes after the IMF southward turning impinges on the magnetopause (eg. Baker et al., 1983). Hence the velocity of expansion of the boundary of the open flux region is :

$$
v=\frac{d s}{d t}=\frac{1}{2} \sqrt{\frac{\phi}{B_{i} \pi t}} \frac{\cos ^{2} \theta+c^{2} \sin ^{2} \theta}{c}
$$

The distance $s$ and the angle $\theta$ are defined by figure $4 a$, and $c$ is assumed not to vary with $t$. From the AMPTE data, the energy coupling factor, $\varepsilon$ (as defined by Reiff et al.,1981), can be computed for immediately before and after the southward turning, regression equations from Reiff et al. give a value for the cross polar-cap potential for a steady-state polar cap, $\phi_{S}$, as a function of $\varepsilon$. The values of $\varepsilon$ before and after the southward turning give $\phi_{S}$ of $30 \mathrm{kV}$ and $170 \mathrm{kV}$ respectively, hence a value of $140 \mathrm{kV}$ is taken here for $\phi$.

(a)
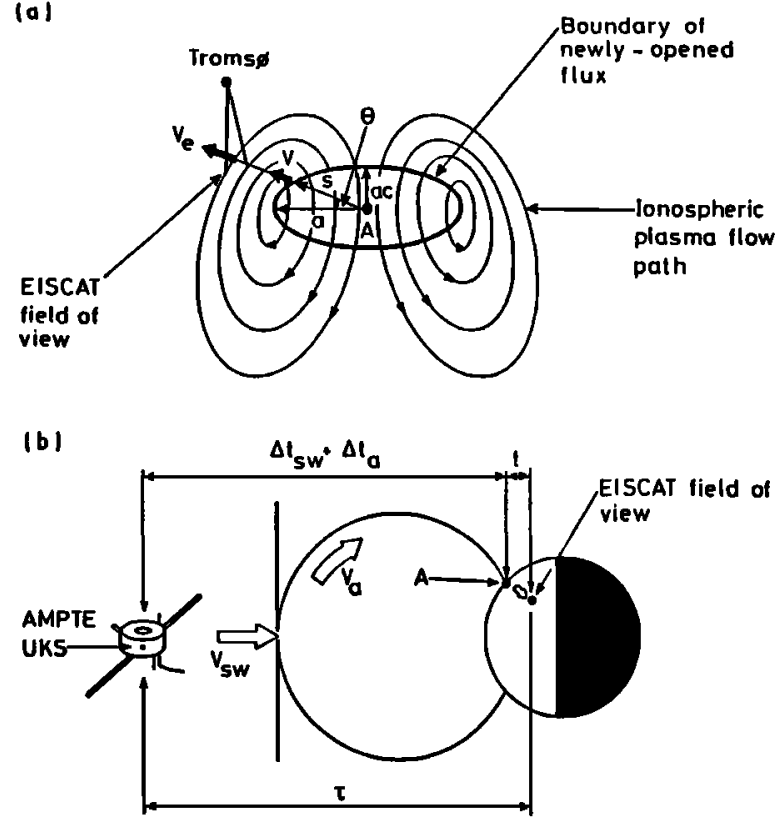

Fig. 4. (a) A twin vortex pattern of the kind set up by an elliptical region of open flux centred on the point A. (b) Schematic illustration of the origin of the delay, , between the IMF change seen at the AMPTE UKS and the apparent F-region response seen by EISCAT. From the solar wind and Alfvén propagation speeds, $v_{S W}$ and $v_{\alpha}$ respectively, $\Delta t_{s w}$ and $\Delta t_{\alpha}$ can be estimated, giving $t$, the delay between ionospheric flux tubes (at the point A) first becoming open to the IMF and the convection enhancement being observed at EISCAT. 
Figure 4b demonstrates how a value for $t$ can be estimated. From UKS observations of the solar wind speed, Rishbeth et al. (1985) estimated the delay between the IMF change passing the UKS and reaching the sub-solar magnetopause to be $\Delta t_{s w}=$ $4 \pm 1$ minutes, and the propagation time of Alfvén waves along geomagnetic field lines from the magnetopause to the cusp ionosphere to be $\Delta t_{\mathrm{q}}=2$ \pm 1 minutes. As the temperature and convection enhancements are first observed $\tau(=11 \pm 1)$ minutes after the IMF change seen by the UKS, $t$ can be estimated to be $\left(\tau-\Delta t_{s w}-\Delta t_{a}\right)=5 \pm 3$ minutes. Using $B=5 \times 10^{5}$ Tesla, equation (2) yields a range for $v$ between 1.4 and $0.7 \mathrm{kms}^{-1}$ for a circular region of open flux $(c=1)$, as used by Siscoe and Huang. These are of the same order of magnitude as the observed eastward velocities but are a factor of about 2 smaller; the difference could have arisen because EISCAT observes the velocity of expansion of the equipotential and ion temperature contours set up by the open field region ( $v_{e}$ in figure $4 a$ ), rather than the velocity of the boundary of that region ( $v$ ). Equation (2) shows that higher $v$ would result from a non-circular open flux region (for example with $c<1$ for $\theta=0$ ).

From both the $T_{i}$ and the $v_{T}$ data, it is found that the centre of the new convection pattern (point $A$ in figure 4, which maps to the point on the magnetopause where merging commenced) was somewhere between 1120 and 1300 MLT. The EISCAT observations are near 1400 MLT and this analysis show that the additional lag between the sudden changes in the AMPTE and EISCAT data, as identified by Rishbeth et al.(1985), can be explained by this simple model of the expansion of the new, enhanced convection pattern from a centre which is located nearer to local noon. The predominant1y eastward direction of the expansion implies that $\theta \simeq 0$ and that the latitude of $A$ is not far to the north of the POLA field of view.

\section{Conclusions}

Very high time resolution data from EISCAT show that ion temperature and line-of-sight velocity changes observed 11 minutes after a southward turning of the IMF, were propagated eastward around the afternoon sector with speeds of the order of $1 \mathrm{kms}^{-1}$. Such expansion speeds are expected from simple considerations of the onset of steady field line merging at the magnetopause and explain the additional delay before enhanced convection is observed at a location away from the ionospheric footprint of the initial merging region, i.e. outside the cusp region. These EISCAT data are the first of sufficiently high time resolution to show how a pattern of sluggish convective flow, characteristic of a northward orientation of the IMF, rapidly evolves into an enhanced pattern, of the kind expected for a southward IMF.

Acknowledgements. We thank the Director and staff of EISCAT for their help and Dr D.J. Southwood for the provision of the AMPTE-UKS magnetometer data. EISCAT is supported by the U.K. SERC, French CNRS, West German MPG, Norwegian NAVF, Swedish NFR and Finnish SA. AMPTE is a collaborative project of NASA (USA), DFVLR and MPG of West Germany and SERC of U.K.

\section{References}

Baker, D.N., R.D. Zwickl, S.J. Bame, E.W. Hones, Jr., B.T. Tsurutani, E.J. Smith, and S.-t. Akasofu, An ISEE3 high time resolution study of Interplanetary parameter correlations with magnetospheric activity, J. Geophys. Res., 88, 6230-6242, 1983.

Clauer, C.R., P.M. Banks, A.Q. Smith, T.S. Jorgensen, E. Friis-Christensen, S. Vennerstrom, V.B. Wickwar, J.D. Kelley, J. Doupnik, Observation of Interplanetary Magnetic Field and of ionospheric plasme convection in the vicinity of the dayside polar cleft, Geophys. Res. Lett., 11, 891-894, 1984.

Clauer, C.R., and Y. Kamide, DP1 and DP2 current systems for the March 22, 1979 substorms, J. Geophys. Res., 90, 1343-1354, 1985.

van Eyken, A.P., H. Rishbeth, D.M. Willis, and S.W.H. Cowley, Initial EISCAT observations of plasma convection at invariant latitudes 70-77, J.atmos.terr.Phys., 46, 635-641, 1984.

Friis-Christensen, E., Y. Kamide, A.D. Richmond, and S. Matsushita, Interplanetary Magnetic Field control of high-latitude electric fields and currents determined from Greenland magneto- meter data, J. Geophys. Res., 90, 1325-1338, 1985 .

Heelis, R.A. and Reiff, P.H., Observations of magnetospheric convection from low altitudes, Adv. Space Sci., 5, 349-362, 1985.

McPherron, R.L., R.H. Manka, Dynamics of the 1054UT March 22,1979, substorm event:CDAW6, J. Geophys. Res., 90, 1175-1190, 1985.

Nishida, A.,Coherence of geomagnetic DP2 fluctuations with interplanetary magnetic variations, J. Geophys. Res., 73, 5549-5559, 1968

Reiff, P.H., R.W. Spiro, and T.W. Hill, Dependence of polar cap potential drop on interplanetary parameters, J.Geophys.Res., 86, 7639-7648, 1981 .

Rishbeth, H., P.R. Smith, S.W.H. Cowley, D.M. Willis, A.P. van Eyken, B.J.I. Bromage, and $S . R$. Crothers, Ionospheric response to changes in the Interplanetary Magnetic Field observed by EISCAT and AMPTE-UKS, Nature, in press, 1985.

Siscoe, G.L., and T.S. Huang, Polar cap inflation and deflation, J.Geophys.Res., 90, 543-547, 1983.

B.J.I. Bromage, A.P. van Eyken, M.Lockwood and D.M. Willis, Rutherford Appleton Laboratory, Chilton, Didcot, OX11 OQX, U.K.

S.W.H. Cowley, Blackett Laboratory, Imperial College, London SW7 2BZ, U.K.

(Received October 28, 1985; revised December 2, 1985; accepted December 2, 1985) 